\title{
Predictive Factors for Vitamin D Concentrations in Swiss Athletes: A Cross-sectional Study
}

\section{(ㄷ) (1) (우 $\odot$}

\author{
Authors \\ Simeon Joel Zürcher ${ }^{1}$, Andrea Quadri², Andreas Huber ${ }^{3}$, Lothar Thomas ${ }^{4}$, Graeme Leonard Close ${ }^{5}$, Saskia Brunner ${ }^{3}$, \\ Patrik Noack $^{6}$, Boris Gojanovic ${ }^{7}$, Susi Kriemler ${ }^{1}$
}

\section{Affiliations}

1 Epidemiology, Biostatistics and Prevention Institute, University of Zürich, Zürich, Switzerland

2 Spital Bulach, Internal Medicine, Bulach, Switzerland

3 Kantonsspital Aarau, Labaratory Medicine, Aarau, Switzerland

4 Klinikum der Johann-Wolfgang-Goethe Universität, Central laboratory for Clinical Chemistry and Hematology, Frankfurt am Main, Germany

5 LJMU, Sports Science, Liverpool, United Kingdom of Great Britain and Northern Ireland

6 Medbase Abtwil, Swiss Olympic Medical Center, Abtwil, Switzerland

7 Hopital de la Tour, Swiss Olympic Medical Center, Meyrin, Switzerland

Key words

25(OH)D, 25-Hydroxyvitamin D, Pre-participation examination, Supplementation, Season, Youth

received 20.03 .2018

revised 13.07 .2018

accepted 18.07.2018

\section{Bibliography}

DOI https://doi.org/10.1055/a-0669-0791

Sports Medicine International Open 2018; 2: E148-E156

(c) Georg Thieme Verlag KG Stuttgart · New York

ISSN 2367-1890

\section{Correspondence}

Ms. Susi Kriemler

Prof. Dr. med.

Epidemiology, Biostatistics and Prevention Institute

Hirschengraben 84

8001 Zürich

Switzerland

Tel.: +41/44/634 6320 $\bigoplus$ Supporting Information for this article is available online at http://www.thieme-connect.de/products

\begin{abstract}
Vitamin D concentrations corresponding to $75 \mathrm{nmol} / \mathrm{L} 25(\mathrm{OH})$ $\mathrm{D}$ have been associated with maintained muscle function, growth and regeneration, optimal bone health and immunology in athletes. The objective of this study was to investigate the prevalence and predictors of insufficient $25(\mathrm{OH}) \mathrm{D}$ concentrations in athletes. Six hundred three Swiss athletes were assessed. $25(\mathrm{OH}) \mathrm{D}$ was analysed by high-performance liquid chromatography (HPLC). A standardized questionnaire was used to gather information about potential predictors for $25(\mathrm{OH}) \mathrm{D}$ concentrations; $50.5 \%$ showed insufficient $25(\mathrm{OH}) \mathrm{D}$ concentrations. Differences in predicted probability of insufficient 25(OH)D were found for those vitamin D supplemented (42\%) versus not supplemented (52\%), in those performing indoor ( $58 \%$ ) versus outdoor sports (43\%), and during the sun-deprived seasons of fall (49\%), winter (70\%) and spring (57\%) compared with summer (17\%). Higher BMI z-scores and age were associated with higher $25(\mathrm{OH}) \mathrm{D}$ concentrations. In conclusion, insufficient $25(\mathrm{OH}) \mathrm{D}$ concentrations were common among athletes especially at a younger age, among those not supplemented, in athletes who trained indoors, and during the sun-deprived seasons. Because the prevalence of insufficient 25(OH)D concentrations in this study was high, regular supplementation in athletes may be indicated, except perhaps during the summer season. Further research is needed to determine which $25(\mathrm{OH}) \mathrm{D}$ concentrations lead to optimal health and performance in athletes.
\end{abstract}




\section{Main Points}

- Desirable vitamin D concentrations corresponding to $75 \mathrm{nmol} / \mathrm{L}$ of 25(OH)D or more have been associated with improved muscle function, regeneration and performance, optimal bone health and immune function in athletes.

- The prevalence of insufficient vitamin D concentrations was high with one in two athletes presenting insufficient concentrations of 25(OH)D ( $<75 \mathrm{nmol} / \mathrm{L})$.

- Younger age, type of sport with mainly indoor training, the lack of vitamin D supplementation, lower BMI, and the sun-deprived seasons (fall, winter and spring) were found to be potential risk factors for low 25(OH)D concentrations.

- Vitamin D supplementation in athletes should be considered, especially during sun-deprived seasons.

\section{Introduction}

Higher vitamin D concentrations [25(OH)D] are associated with multiple health benefits such as higher bone mass and acquisition, and protective effects against cardiovascular diseases, cancer and other chronic diseases $[4,26]$. Nevertheless, there is still controversy about the clinical relevance of 25(OH)D [55]. In general, $25(\mathrm{OH}) \mathrm{D}$ is increased by sun radiation (sun angle $>30^{\circ}$ ) on noncovered skin, nutrition, and vitamin $\mathrm{D}$ supplementation, and decreased by various diseases (e. g. obesity, liver failure) [26]. Further studies suggest that higher age [30], higher BMI or fat mass $[24,49]$, darker skin colour [8,9], sunscreen use [27,36], and indoor compared to outdoor sports activities $[14,35,44]$ are associated with lower $25(\mathrm{OH}) \mathrm{D}$ concentrations as an expression of inadequate intake or production by the skin or altered metabolic pathways. The influence of sex is controversial $[30,37]$.

On a population level, most international authorities classify $25(\mathrm{OH}) \mathrm{D}$ of $>50 \mathrm{nmol} / \mathrm{L}$ as sufficient and $\geq 75 \mathrm{nmol} / \mathrm{L}$ as desirable $[11,12,27,41,47]$. The higher $75 \mathrm{nmol} / \mathrm{L}$ target is supported by studies that show multiple beneficial effects such as increased peak bone mass and mineral density, muscle strength, a maximal suppression of parathyroid hormone, optimized intestinal calcium resorption and immunological benefits $[4,11,20,23,26,27]$.

In athletes, circulating $25(\mathrm{OH}) \mathrm{D}$ has been associated with maintained muscle function including improvements in muscle contractions, enhanced growth and regeneration following muscle damage, and optimal bone health $[7,17,43,48,56]$. Athletes with desirable 25(OH)D concentrations show an improved immune function including, but not limited to, lower incidence of upper respiratory tract infections $[20,28]$. Yet, inadequate concentrations of $25(\mathrm{OH}) \mathrm{D}$ are highly prevalent in athletes especially during the winter months [3, 14].

Several predictors of vitamin D insufficiency have been reported in the past that allow detecting populations at risk that may deserve more preventive attention. Because we are dealing with an athlete population that may differ from the general population, predictors from the general population (e. g. age, sex, BMI, skin colour and protection, vitamin $\mathrm{D}$ substitution, season, latitude) may differ $[8,9,27,30,36,37,49]$, and selective factors in athletes such as training hours or location of sports activity as a proxy for sun exposure may play a role [14].
Previous studies that investigated the prevalence and predictors of insufficient $25(\mathrm{OH}) \mathrm{D}$ in athletes lacked external validity, limiting their generalisability for central Europe (e. g. Switzerland) due to different reasons: studies used different analytical approaches for 25(OH)D concentrations (e. g. RIA, CLIA) which affects comparability of results $[2,14,18,34,50]$, included non-comparable populations (e. g. Northern countries like the UK, other races as in Qatar, Middle East) $[10,14,18]$, used small sample sizes of $<30$ $[14,16,63,64]$, or focussed on only one specific season or selective predictors without controlling for others [14].

To address the study limitations mentioned, the objective of this study was to assess the prevalence and predictors of insufficient $25(\mathrm{OH}) \mathrm{D}$ concentrations by conducting a cross-sectional study on a large diverse (e. g. age, type of sport) sample of competitive athletes in Switzerland over the period of one year. We hypothesised a high prevalence of vitamin D insufficiency and variables like sex, age, BMI, vitamin D substitution, skin colour, sunscreen use, hours of training (proxy variable for sun exposure), location of sport activities (indoor vs. outdoor sports), and season to be associated with 25(OH)D concentrations.

\section{Materials and Methods}

\section{Participants}

This is a cross-sectional study that was conducted on a convenience sample of 603 Swiss Olympic athletes corresponding to $3.4 \%$ of a total of 17,927 active Swiss Olympic card holders [54]. All athletes with a National Olympic Committee (Swiss Olympic) card reflecting a regional, national or international competitive sport level were eligible to participate. No other eligibility criteria were applied. All participants were healthy (e. g. no diagnosis of renal insufficiency). A total of 24 (out of 39) National Olympic Committeeaccredited sports medical centres participated in the study and recruited study participants during the pre-participation evaluation (PPE) over a period of 13 months (5/2014-6/2015). Participation was voluntary for centres. The PPE by the physician included a medical examination, routine blood sample examination and the completion of a questionnaire. Blood samples were processed and analysed at a single certified central laboratory (Canton hospital Aarau AG, Aarau, Switzerland) after being sent by express mail within $12 \mathrm{~h}$. Participation was voluntary and written informed consent was obtained for all participants. Data protection was ensured through pseudonymisation. According to Swiss regulations no ethical approval from national authorities had to be obtained for this type of study, which met the ethical standards in sport and exercise science research [19].

\section{Vitamin D}

Vitamin D (cholecalciferol/25-hydroxyvitamin D3) was analysed using a kit for the quantification of vitamin D2 and vitamin D3 (PerkinElmer, Turku, Finland). The kit employed isotope dilution and HPLC coupled with mass spectrometry (ID-LC-APCI-MS/MS) and was installed on an Ultimate $3000 \mathrm{HPLC}$ (Thermo Fisher, Waltham, MA, USA) and a QTRAP 5500 mass spectrometer (Sciex, Framingham, MA, USA) [50,57]. The detection limit (detection of lowest concentration) was $5 \mathrm{nmol} / \mathrm{L}$. According to the manufacturer, 
intra-assay variability is between 4.45 and $5.0 \%$ and inter-assay variability lies between $4.3 \%$ and $5.6 \%$. For the main analysis, $25(\mathrm{OH}) \mathrm{D}$ was dichotomized, with concentrations $<75 \mathrm{nmol} / \mathrm{L}$ defining insufficient and concentrations $\geq 75 \mathrm{nmol} / \mathrm{L}$ defining desirable levels.

\section{Predictors}

Information about sociodemographic factors, sports and training, clinical information, clinical symptoms and further variables potentially related to $25(\mathrm{OH}) \mathrm{D}$ was gathered via a questionnaire. Age was included in years. Body mass index (BMI, kg/m2) and BMI-for-age z-scores were calculated according to the World Health Organization references (athletes above 19 years were set to 19 years) [65]. Season was categorized based on the four astronomic seasons that take solar radiation into account; spring (March 21 to June 20), summer (June 21 to September 20), fall (September 21 to December 20) and winter (21 December to 20 March). The main sport activities were divided into indoor sports (e. g. hockey, gymnastics, swimming) and outdoor sports (e. g. football, snow sports, marathon). Training hours were assessed as average hours per week over the last three months. Skin colour was assessed at five levels and subsequently dichotomized into fair skin (pale/fair skin, fair skin = northern European and Scandinavian type) and dark skin (brown, dark skin and black = southern European, Indian, and African type) due to low case numbers in some categories [15]. Sunscreen use was rated on a 5-point Likert scale from regular to never use (in $100 \%, 75 \%, 50 \%, 25 \%$, or $0 \%$ of time). The first three answers were categorized as "regular" use and the latter two as "seldom/never". Information about vitamin D (cholecalciferol) supplementation was collected by asking for intake frequency, dosage and the trade name. All reported supplements were checked for cholecalciferol/ergocalciferol content, but exact dosage IU could not be determined due to partially imprecise product information from participants. A binary variable (yes/no) was coded indicating cholecalciferol/ergocalciferol supplementary intake. If no trade name was stated for multivitamins, vitamin D supplementation was assumed and coded as "yes".

\section{Statistical analysis}

Sample characteristics are presented as means \pm standard deviations (SD) for continuous variables and as counts and frequencies for categorical variables. The two sample proportion (z-test) or chisquared test was used to detect differences in 25(OH)D (insufficient versus desirable) fractions for each level of all independent categorical variables. Mean differences of continuous variables (across the binary outcome variable) were tested by independent t-test with unequal variances (Welch's t-test).

A binary logistic regression (main model) was calculated to detect potential risk factors of $25(\mathrm{OH}) \mathrm{D}$ concentrations $<75 \mathrm{nmol} / \mathrm{L}$. Coefficients are reported as odds ratio including $95 \%$ confidence interval. To obtain additional information on the extent of influence of the predictors, a multiple linear regression was calculated reporting beta coefficients and $95 \%$ confidence interval. To minimize potential bias, loss of precision and power due to item non-response (missing values of single athlete on one or more variables), we imputed the data $(\mathrm{m}=40)$ using a chained equation approach (MI) [51, 52, 62]. All variables used in the analytical models were also used in the imputation models including the outcome [38,51]. Additionally, a com- plete case analysis (CCA) was performed in order to compare the results with the multiple imputation-based analysis (differences between complete case and imputed analysis are reported). Predicted probabilities of all independent variables (predictive margins) including a $95 \%$ confidence interval (holding other variables constant at their mean values) were calculated to graphically display the effects of the predictors in the logistic regression model. Data analysis was performed using Stata for Windows version 13.1 (StataCorp LP, College Station, TX, USA).

\section{Results}

The characteristics of the total sample of athletes and athletes stratified by $25(\mathrm{OH}) \mathrm{D}$ categories (desirable $\geq 75 \mathrm{nmol} / \mathrm{L}$ or insufficient $<75 \mathrm{nmol} / \mathrm{L}$ ) are shown in $>$ Table 1 . Athletes ( $63 \%$ male) ranged from 9 to 46 years of age and showed a mean (SD) weight of 63.4 (15.1). Missing values were present for BMI, training hours, skin colour, sunscreen use, and outdoor/indoor sports ranging from 0.3 to $15.6 \%$.

Insufficient $25(\mathrm{OH}) \mathrm{D}$ concentrations $<75 \mathrm{nmol} / \mathrm{L}$ were present in $50.5 \%$ of athletes while a deficiency $<50 \mathrm{nmol} / \mathrm{L}$ was present in $14 \%$. Insufficient concentrations of $25(\mathrm{OH}) \mathrm{D}$ were significantly more prevalent in females, in athletes without vitamin $D$ supplementation, and in fall, winter and spring compared with summer. Age, BMI (unstandardised and standardised), and training hours per week were significantly lower in athletes with insufficient $25(\mathrm{OH})$ D concentrations compared with the desirable group. Mean (SD) and median (interquartile range) 25(OH)D concentrations were 75.9 (23.4) and 74.8 (31.3) nmol/L, respectively. Further sample characteristics (type of sport) are given in Appendix Table 1S).

Tested predictors of insufficient 25(OH)D concentrations investigated by logistic and linear regression are shown in $>$ Table 2 . By logistic regression, younger age, lower BMI z-scores, the lack of vitamin D supplementation, indoor versus outdoor sport activities and the seasons of fall, winter, and spring as compared with summer significantly increased the probability of insufficient $25(\mathrm{OH}) \mathrm{D}$. - Fig. 1-3 summarize the mean-adjusted predicted probabilities of insufficient $25(\mathrm{OH}) \mathrm{D}$ concentrations for all categorical predictors, age and BMI z-scores. Differences in probability of insufficient $25(\mathrm{OH})$ D were found for indoor $(58.5 \%)$ versus outdoor sports (42.5\%), the lack of vitamin D supplementation (52.4\%) versus supplementation (42.0\%) and during the sun-deprived seasons of fall (49.5\%), winter (70.3\%) and spring (57.3\%) as compared with summer $(17.0 \%)$. Higher predicted probabilities of insufficient $25(\mathrm{OH})$ $D$ were also found for younger as compared with older age and for lower compared with higher BMI z-scores (see > Fig. 2, 3). Similar results were obtained from multiple linear regressions (adjusted for all other variables). A one-unit increase in age (year) and BMI zscore was associated with an increase of $0.85 \mathrm{nmol} / \mathrm{L}$ and $3.04 \mathrm{mmol} / \mathrm{L} 25(\mathrm{OH}) \mathrm{D}$, respectively. Likewise, 25(OH)D concentrations were significantly lower in the group without than with vitamin D supplementation $(-5.1 \mathrm{nmol} / \mathrm{L})$, in indoor than outdoor sports $(-5.4 \mathrm{nmol} / \mathrm{L})$ and during fall $(-16.9 \mathrm{nmol} / \mathrm{L})$, winter $(-28.6 \mathrm{nmol} / \mathrm{L})$, spring $(19.7 \mathrm{nmol} / \mathrm{L})$ compared to summer. Minor differences in results based on the multiple imputation as compared to the complete case analysis occurred but did not change the conclusion. 


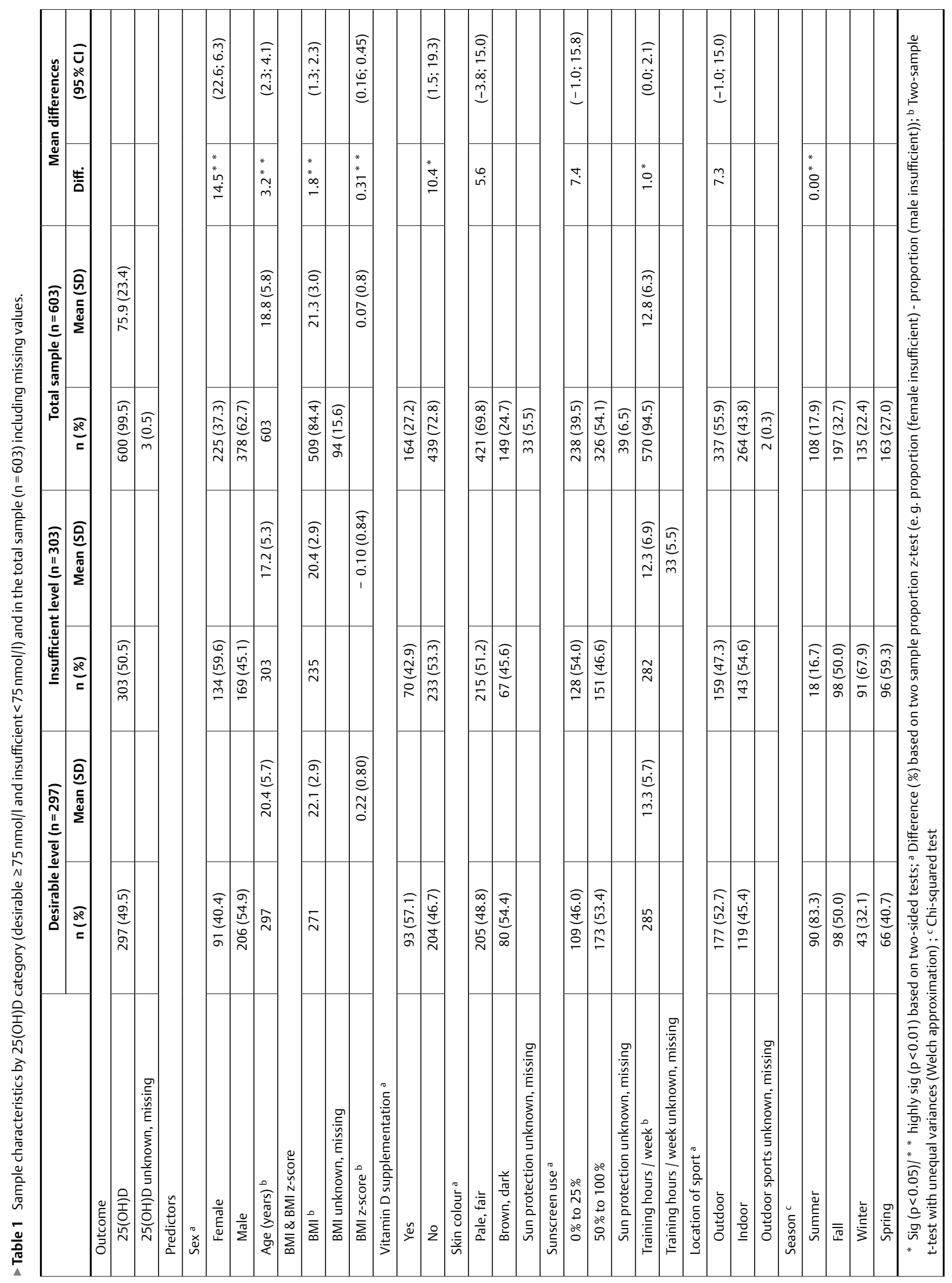


- Table 2 Predictors of 25(OH)D concentrations ( $<75 \mathrm{nmol} / \mathrm{l}$ ) by logistic regression (insufficient $<75 \mathrm{nmol} / \mathrm{l} 25(\mathrm{OH}) \mathrm{D}$ vs. desirable $\geq 75 \mathrm{nmol} / \mathrm{l} 25(\mathrm{OH}) \mathrm{D}$ ) and linear regression $(n=603)$.

\begin{tabular}{|c|c|c|c|c|c|c|}
\hline & \multicolumn{3}{|c|}{ Logistic regression (insufficient vs. desirable) } & \multicolumn{3}{|c|}{ Linear regression (prediction of continuous levels of $25(\mathrm{OH}) \mathrm{D}$ ) } \\
\hline & OR & $(95 \% \mathrm{Cl})$ & p-value & Beta coef. & $(95 \% \mathrm{Cl})$ & p-value \\
\hline \multicolumn{7}{|l|}{ Sex } \\
\hline Male & Reference & & & Reference & & \\
\hline Female & 1.29 & (0.88 to 1.90$)$ & 0.20 & 0.41 & $(-3.09$ to 3.92$)$ & 0.82 \\
\hline Age (years) & 0.93 & (0.89 to 0.97$)$ & $<0.001$ & 0.85 & $(0.52$ to 1.18$)$ & $<0.001$ \\
\hline BMI z-scores WHO & 0.77 & $(0.60$ to 1.00$)$ & 0.046 & 3.04 & $(0.83$ to 5.24$)$ & 0.007 \\
\hline \multicolumn{7}{|c|}{ Vitamin D supplementation } \\
\hline No & Reference & & & Reference & & \\
\hline Yes & 0.66 & (0.43 to 0.99 ) & 0.045 & 5.12 & (1.39 to 8.85 ) & 0.007 \\
\hline \multicolumn{7}{|l|}{ Skin color } \\
\hline Light, very light & Reference & & & Reference & & \\
\hline Brown, black & 0.85 & (0.55 to 1.32 ) & 0.48 & -0.80 & (-4.63 to 3.04$)$ & 0.68 \\
\hline \multicolumn{7}{|l|}{ Sunscreen use } \\
\hline $0 \%$ to $25 \%$ & Reference & & & Reference & & \\
\hline $50 \%$ to $100 \%$ & 0.85 & (0.58 to 1.25 ) & 0.41 & 1.04 & $(-2.42$ to 4.50$)$ & 0.55 \\
\hline $\begin{array}{l}\text { Training hours } \\
\text { (week) }\end{array}$ & 1.01 & (0.97 to 1.04 ) & 0.68 & 0.15 & $(-0.15$ to 0.44$)$ & 0.33 \\
\hline \multicolumn{7}{|l|}{ Location of sport } \\
\hline Indoor sports & Reference & & & Reference & & \\
\hline Outdoor sports & 0.53 & (0.34 to 0.82$)$ & 0.004 & 5.38 & (1.55 to 9.20$)$ & 0.006 \\
\hline \multicolumn{7}{|l|}{ Season } \\
\hline Summer & Reference & & & Reference & & \\
\hline Fall & 4.78 & (2.49 to 9.19 ) & $<0.001$ & -16.91 & $(-22.20$ to -11.61$)$ & $<0.001$ \\
\hline Winter & 11.49 & (5.68 to 23.23 ) & $<0.001$ & -28.58 & $(-34.28$ to -22.89$)$ & $<0.001$ \\
\hline Spring & 6.59 & (3.45 to 12.57 ) & $<0.001$ & -19.71 & (-24.91 to -14.52$)$ & $<0.001$ \\
\hline
\end{tabular}

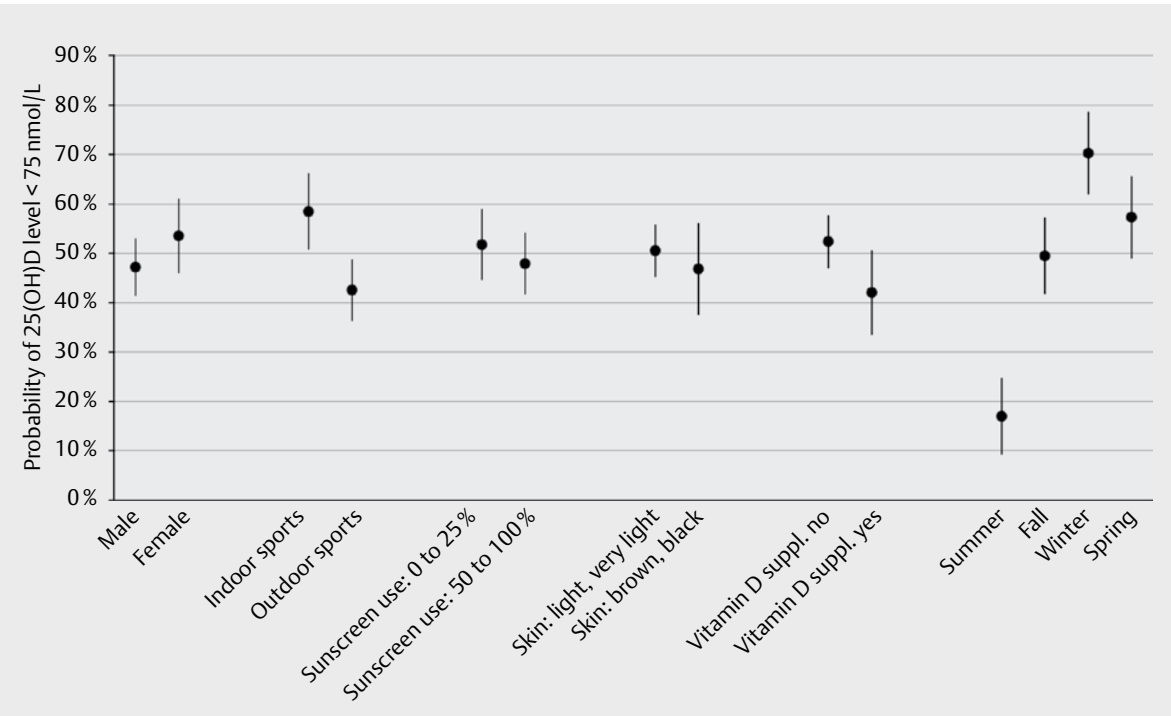

- Fig. 1 Mean-adjusted predicted probabilities of $25(\mathrm{OH}) \mathrm{D}$ concentrations $<75 \mathrm{nmol} / \mathrm{L}$ ( $95 \%$ confidence interval) for categorical variables derived from the logistic regression model $(n=603)$. Predictions are mean-adjusted for all other variables listed in $>$ Table 2. Significantly higher probabilities of 25(OH)D insufficiency were present for indoor vs. outdoor sports, not supplemented vs. supplemented athletes, and in fall, winter and spring compared to summer. 


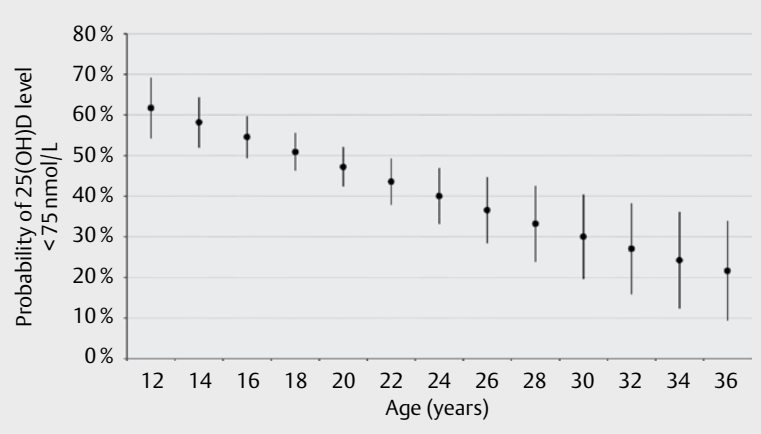

- Fig. 2 Mean-adjusted predicted probabilities of 25(OH)D concentrations $<75 \mathrm{nmol} / \mathrm{L}$ ( $95 \%$ confidence interval) for different age groups derived from the logistic regression model $(n=603)$. Predictions are mean-adjusted for all other variables listed in $>$ Table 2 . Higher age was significantly related to lower probability of $25(\mathrm{OH}) \mathrm{D}$ insufficiency.

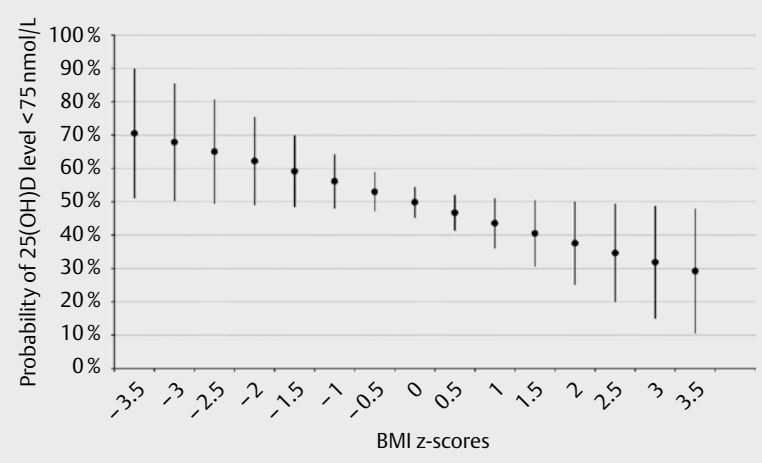

- Fig. 3 Mean-adjusted predicted probabilities of 25(OH)D concentrations $<75 \mathrm{nmol} / \mathrm{L}$ (95\% confidence interval) for different BMI $z$-scores derived from the logistic regression model $(n=603)$. Predictions are mean-adjusted for all other variables listed in $>$ Table $\mathbf{2}$. Higher BMI z-scores were significantly related to lower probability of 25(OH)D insufficiency.

\section{Discussion}

This cross-sectional study in a large cohort of Swiss athletes demonstrated that one in two Swiss athletes showed insufficient 25(OH)D below $75 \mathrm{nmol} / \mathrm{L}$, potentially compromising health and athletic performance. Lower age, lower BMI and the seasons fall, winter and spring showed to be risk factors for insufficient 25(OH)D concentrations, whereas vitamin $\mathrm{D}$ supplementation and outdoor sports were positively related to $25(\mathrm{OH}) \mathrm{D}$ concentrations. Sex, skin colour, sun cream use and training hours did not significantly predict $25(\mathrm{OH}) \mathrm{D}$ levels.

\section{Prevalence insufficient 25(OH)D concentrations}

The prevalence of insufficient $25(\mathrm{OH}) \mathrm{D}$ of approximately $51 \%$ shown in this study was comparable to previous research in athletes (56\%) and somewhat lower than in the general population $(64-70 \%)[6,14,37]$. This is not surprising because $25(\mathrm{OH}) \mathrm{D}$ levels can be influenced by many factors. These include age, BMI, ethnic- ity, different skin types, sun protection approaches (e. g. sunscreen use, clothing), latitude of residence, and seasonal variation determining the extent of sun exposure, as well as dietary intake and supplementation [14, 26, 31]. Irrespective of personal and environmental factors, 25(OH)D measurement approaches are subject to high variability which may result in different prevalence estimates of insufficient $25(\mathrm{OH}) \mathrm{D}$ concentrations ranging from 8 to $42 \%$ [50].

\section{Season}

In this study, season was the strongest predictor of $25(\mathrm{OH}) \mathrm{D}$ concentrations with the sun-deprived seasons of fall, winter and spring as compared to summer as the strongest risk factors for insufficient $25(\mathrm{OH}) \mathrm{D}$ concentrations. This finding is consistent among studies $[14,35]$ as during these seasons, the zenith angle to the earth is too shallow $\left(<45^{\circ}\right)$ to induce any vitamin D production in the skin [32]. Moreover, colder temperatures during these sun-deprived seasons requires proper clothing that covers the skin completely and prevents any natural production of vitamin $D$.

\section{Age and sex}

Higher age was associated with lower odds of insufficiency and therefore higher 25(OH)D concentrations. This was not expected based on epidemiological data [30] because $25(\mathrm{OH}) \mathrm{D}$ production in the skin becomes less efficient with increasing age due to a lower 7-dehydrocholesterol content in the epidermal layer of the skin [33]. We doubt that this mechanism played a relevant role in our rather young population, because the decrease in vitamin $D$ production efficiency seems to be especially prominent at an older age $[13,33]$. Yet, the rising awareness of the carcinogenic effect of UV radiation over the last several decades may have led to preventive strategies with the avoidance of sun exposure and the unconditional use of sun cream [40]. The younger athletes might have been more aware of this, potentially due to the influence of their healthconscious parents.

The influence of sex on $25(\mathrm{OH}) \mathrm{D}$ concentrations is controversial. Some authors found lower $25(\mathrm{OH}) \mathrm{D}$ concentrations in females, whereas others found the opposite pattern [30, 37, 39, 61]. In this study, a higher prevalence of insufficient $25(\mathrm{OH}) \mathrm{D}$ concentrations was found in females (compared to males), which is likely explained by other factors such as different body mass, fat percentage or time spent in the sun. It is not surprising, however, that the gender difference disappeared after adjusting for all other variables in the models.

\section{BMI, skin colour \& sunscreen use}

Several studies suggest an inverse relation between BMI, fat mass and vitamin D concentrations $[24,49]$ because body fat serves as $25(\mathrm{OH}) \mathrm{D}$ storage and reduces its release [46]. We found weak evidence for the opposite scenario with a small but consistent positive association between BMI (z-scores) and 25(OH)D concentrations. In athletes, a higher BMI is generally not a marker of higher body fat, but rather of increased muscle mass. It is known that $25(\mathrm{OH}) \mathrm{D}$ plays an important role in muscle function such as induction of myogenic transcription, cell proliferation and differentiation, and suppression of myostatin. Therefore, higher muscle mass, expressed in our study as a higher BMI, possibly goes along with higher $25(\mathrm{OH}) \mathrm{D}[1,29]$. Another explanation for this positive rela- 
tion in athletes could be the lower intake of dietary vitamin $D$ in athletes with a lower BMI. A low dietary and therefore 25(OH)D intake and even eating disorders are common among sports athletes where low body weight might be an advantage such as in aesthetic or endurance sports [53]. But, whether and how much deficient dietary intakes play a role is still controversial. For instance, an investigation of a large cohort identified that less than $2 \%$ of individuals studied met dietary intake requirements (RDA) for vitamin D, which questions the relevance of nutrition in the prevention of vitamin D deficiency [25].

Darker skin colour (more melanin) and frequent sunscreen use are relevant barriers of $25(\mathrm{OH}) \mathrm{D}$ production and therefore associated with a lower production of pre-vitamin $\mathrm{D}$ in the skin and consequently lower circulating 25(OH)D concentrations [8, 9, 27, 36]. Surprisingly, both factors were not found to be significant predictors of insufficient 25(OH)D concentrations in our statistical models, which may be partly explained by the lack of measurement precision (questionnaire data).

\section{Vitamin D supplementation}

Levy, McKinnon, Barker, et al. [31] found that vitamin D supplementation in a general population was the strongest positive predictor of circulating 25(OH)D concentrations. Although vitamin D supplementation was associated with a $5 \mathrm{nmol} / \mathrm{L}$ higher $25(\mathrm{OH}) \mathrm{D}$ concentration compared to the not supplemented group, this difference is surprisingly small. This can be explained partly by the variation in supplemental dose of vitamin D. The majority of athletes in our study reported taking supplemental vitamin D, mostly in the form of a multivitamin supplements. Due to the imprecise recall of the exact name of the supplements by the athletes, the supplementation dosage could not be specified exactly, although most multi-vitamin supplements contain 400 IU of vitamin D [26] and may not be sufficient to reach the recommended daily allowance (RDA) levels of 600-800 IU/day [12, 27, 47]. Heaney [21] found that, depending on the baseline $25(\mathrm{OH}) \mathrm{D}$, an increase between $6 \mathrm{nmol} / \mathrm{L}(2.4 \mathrm{ng} / \mathrm{ml})$ and $10 \mathrm{nmol} / \mathrm{L}(4 \mathrm{ng} / \mathrm{ml})$ is expected with supplementation of $400 \mathrm{IU} /$ day, which is close to our estimate. In addition, poor compliance in taking supplements or even medications (approximately $50 \%$ in other populations) may have contributed to the apparently low vitamin D concentrations despite supplementation $[5,66]$.

\section{Indoor sports and training hours}

Several studies have shown that athletes performing indoor sports rather than outdoor sports are more susceptible to 25(OH)D insufficiency, suggesting a difference in sun exposure [14, 35, 44]. In support of this belief, seasonal variations in $25(\mathrm{OH}) \mathrm{D}$ have been well described in the literature with consistently lower $25(\mathrm{OH}) \mathrm{D}$ concentrations in fall and winter than in summer [14, 27, 35, 42]. We included training hours per week as a possible correlate of $25(\mathrm{OH}) \mathrm{D}$ concentrations as a possible proxy variable for hours of sun exposure. We found higher training hours in the optimal $25(\mathrm{OH}) \mathrm{D}$ group in the descriptive analysis, but this effect disappeared after adjusting for other predictive variables. Therefore, training hours do not seem to be a good proxy for sun exposure, because it highly depends on time and location of training as well as skin protection provided by sunscreen and clothing.

\section{Recommendation and supplementation}

Based on the literature, target concentrations of $75 \mathrm{nmol} / \mathrm{L} 25(\mathrm{OH})$ $D$ may be recommended for athletes to improve performance and regeneration [43] or to offer immunological benefits to prevent acute infection [20]. This target concentration is further supported by benefits to bone health which is an important value especially for younger athletes who may still be growing $[4,11,23,26,27]$. Because the prevalence of insufficient $25(\mathrm{OH}) \mathrm{D}$ concentrations in this study was high, supplementation in athletes may be indicated, except perhaps in the summer months [20]. The intake of at least $600 \mathrm{IU} /$ day vitamin D3 for children and adults is recommended by different authorities (e. g. Endocrine Society, Institute of Medicine) $[12,27,47]$. However, to reach $25(\mathrm{OH})$ D levels of $\geq 75 \mathrm{nmol} / \mathrm{L}$, higher dosages may be needed $[12,27,47,58]$. Daily vitamin D3 supplementation at a dosage between 600 and $1000 \mathrm{IU}$ is generally recommended and considered safe by different authorities $[12,22,27,47]$. Under strict sunlight safety recommendations in summer (e. g. short regular exposure under strict avoidance of sunburn, application of sun cream after about 15 min of exposure) $[59,60]$, supplementation may be replaced by about 15 min of sun exposure (covered with a T-shirt and shorts) on most days. This allows obtaining desirable vitamin D concentrations of $\geq 75 \mathrm{nmol} / \mathrm{L}$ in a majority of supplemented populations $[45,60]$. For those at high risk of sunburn, those who train mostly indoors or wear skin covering/clothing [18], and/or those who fear an increased risk of skin cancer, supplementation can safely be taken throughout the year [22].

\section{Study strength and limitations}

The major strength of this study is the inclusion of a large and variable sample of competitive athletes in Switzerland. 25(OH)D was uniformly assessed by one central and certified quality laboratory that used the gold standard assay of liquid chromatography-mass spectrometry to determine serum concentrations of 25(OH)D [50]. Multiple imputation was used to account for item non-response in the statistical analysis to increase precision and lower the probability of selection bias [52]. Limitations are related to the cross-sectional design precluding causality and the possibility of a selection bias that may have been induced by unit non-response. Moreover, we used questionnaire data to assess demographics and some risk factors prone to different types of bias. Unfortunately, the inclusion of objective measures such as body composition including fat, muscle and bone mass (e. g. by dual X-ray absorptiometry), aerobic endurance or muscle function, or immunological markers was not possible.

\section{Conclusion}

Insufficient 25(OH)D concentrations that potentially hinder health and sport performance are prevalent among athletes, especially during the sun-deprived seasons. Furthermore, those of younger age and with lower BMI, those who participate primarily in indoor sports and do not take vitamin D supplements were at a higher risk for 25(OH)D insufficiency. Vitamin D intake and sun exposure recommendations for athletes should be individually determined taking the aforementioned risk factors into account. Considering the uncertainty of compliance regarding vitamin D supplementation, 
further studies should evaluate whether commercial multi-vitamin supplements that normally contain 400 IU of vitamin D are sufficient to maintain desirable vitamin $D$ levels. Further research is required to establish the range of $25(\mathrm{OH}) \mathrm{D}$ concentrations associated with optimal health and performance in athletes, whether the optimal range differs according to age, type and location of sport performed, and which supplementation doses are needed to reach these optimal 25(OH)D concentrations.

\section{Acknowledgements}

* SK and BG contributed equally to this manuscript (last authorship) Contributors Funding financially supported by Swiss Olympic, the Swiss Society of Sports Medicine (SGSM), and the Epidemiology, Biostatistics and Prevention Institute of the University of Zürich. Competing interests None declared. Contributors: SK, PN, $\mathrm{BG}, \mathrm{AH}$ designed, planed and conducted the study and revised the paper. AQ collected and cleaned the data, performed first analyses and revised the article. SJZ and SK wrote the final article and performed the statistical analyses. GLC, LT and SB contributed expertise and all authors commented, revised and approved the final manuscript.

\section{Conflict of Interest}

The authors declare that they have no conflict of interest

\section{References}

[1] Abboud M, Puglisi DA, Davies BN, Rybchyn M, Whitehead NP, Brock KE, Cole L, Gordon-Thomson C, Fraser DR, Mason RS. Evidence for a specific uptake and retention mechanism for 25-hydroxyvitamin D (25OHD) in skeletal muscle cells. Endocrinology 2013; 154: 30223030

[2] Allison RJ, Close GL, Farooq A, Riding NR, Salah O, Hamilton B, Wilson MG. Severely vitamin $D$-deficient athletes present smaller hearts than sufficient athletes. Eur J Prev Cardiol 2015; 22: 535-542

[3] Bakken A, Targett S, Bere T, Adamuz MC, Tol JL, Whiteley R, Wilson MG, Witvrouw E, Khan KM, Bahr R. Health conditions detected in a comprehensive periodic health evaluation of 558 professional football players. Br J Sports Med 2016; 50: 1142-1150

[4] Bischoff-Ferrari HA, Giovannucci E, Willett WC, Dietrich T, DawsonHughes B. Estimation of optimal serum concentrations of 25-hydroxyvitamin D for multiple health outcomes. Am J Clin Nutr 2006; 84: $18-28$

[5] Brown MT, Bussell JK. Medication adherence: WHO cares? Mayo Clin Proc 2011; 86: 304-314

[6] Burnand B, Sloutskis D, Gianoli F, Cornuz ], Rickenbach M, Paccaud F, Burckhardt P. Serum 25-hydroxyvitamin D: Distribution and determinants in the Swiss population. Am J Clin Nutr 1992; 56 : 537-542

[7] Cannell J], Hollis BW, Sorenson MB, Taft TN, Anderson JJ. Athletic performance and vitamin D. Med Sci Sports Exerc 2009; 41: $1102-1110$

[8] Chen TC, Chimeh F, Lu Z, Mathieu J, Person KS, Zhang A, Kohn N, Martinello S, Berkowitz R, Holick MF. Factors that influence the cutaneous synthesis and dietary sources of vitamin D. Arch Biochem Biophys 2007; 460: 213-217
[9] Clemens TL, Adams JS, Henderson SL, Holick MF. Increased skin pigment reduces the capacity of skin to synthesise vitamin D3. Lancet 1982; 1: 74-76

[10] Constantini NW, Arieli R, Chodick G, Dubnov-Raz G. High prevalence of vitamin D insufficiency in athletes and dancers. Clin J Sport Med 2010; 20: 368-371

[11] Dawson-Hughes B, Heaney RP, Holick MF, Lips P, Meunier PJ, Vieth R. Estimates of optimal vitamin D status. Osteoporos Int 2005; 16: 713-716

[12] Dawson-Hughes B, Mithal A, Bonjour JP, Boonen S, Burckhardt P, Fuleihan GE, Josse RG, Lips P, Morales-Torres J, Yoshimura N. IOF position statement: Vitamin $\mathrm{D}$ recommendations for older adults. Osteoporos Int 2010; 21: 1151-1154

[13] Elizondo-Montemayor L, Castillo EC, Rodriguez-Lopez C, VillarrealCalderon JR, Gomez-Carmona M, Tenorio-Martinez S, Nieblas B, Garcia-Rivas $G$. Seasonal variation in vitamin D in association with age, inflammatory cytokines, anthropometric parameters, and lifestyle factors in older adults. Mediators Inflamm 2017; 2017: 5719461

[14] Farrokhyar F, Tabasinejad R, Dao D, Peterson D, Ayeni OR, Hadioonzadeh $R$, Bhandari M. Prevalence of vitamin D inadequacy in athletes: $A$ systematic review and meta-analysis. Sports Med 2015; 45: 365-378

[15] Fitzpatrick TB. Soleil et peau. J Med Esthet 1975; 2: 33-34

[16] Galan F, Ribas J, Sanchez-Martinez PM, Calero T, Sanchez AB, Munoz A. Serum 25-hydroxyvitamin D in early autumn to ensure vitamin D sufficiency in mid-winter in professional football players. Clin Nutr 2012; 31: 132-136

[17] Goolsby MA, Boniquit N. Bone health in athletes. Sports Health 2016; 9: 108-117

[18] Hamilton B, Grantham J, Racinais S, Chalabi H. Vitamin D deficiency is endemic in Middle Eastern sportsmen. Public Health Nutr 2010; 13: 1528-1534

[19] Harriss DJ, Macsween A, Atkinson G. Standards for ethics in sport and exercise science research: 2018 update. Int J Sports Med 2017; 38: 1126-1131

[20] He CS, Aw Yong XH, Walsh NP, Gleeson M. Is there an optimal vitamin $D$ status for immunity in athletes and military personnel? Exerc Immunol Rev 2016; 22: 42-64

[21] Heaney RP. The vitamin D requirement in health and disease. J Steroid Biochem Mol Biol 2005; 97: 13-19

[22] Heaney RP. Vitamin D: Criteria for safety and efficacy. Nutr Rev 2008; 66: S178-S181

[23] Heaney RP. Health is better at serum 25(OH)D above $30 \mathrm{ng} / \mathrm{mL}$. J Steroid Biochem Mol Biol 2013; 136: 224-228

[24] Heller JE, Thomas J], Hollis BW, Larson-Meyer DE. Relation between vitamin D status and body composition in collegiate athletes. Int J Sport Nutr Exerc Metab 2015; 25: 128-135

[25] Hill KM, Jonnalagadda SS, Albertson AM, Joshi NA, Weaver CM. Top food sources contributing to vitamin $D$ intake and the association of ready-to-eat cereal and breakfast consumption habits to vitamin D intake in Canadians and United States Americans. J Food Sci 2012; 77: $\mathrm{H} 170-\mathrm{H} 175$

[26] Holick MF. Vitamin D deficiency. N Engl ] Med 2007; 357: 266-281

[27] Holick MF, Binkley NC, Bischoff-Ferrari HA, Gordon CM, Hanley DA, Heaney RP, Murad MH, Weaver CM. Evaluation, treatment, and prevention of vitamin D deficiency: An Endocrine Society clinical practice guideline. J Clin Endocrinol Metab 2011; 96: 1911-1930

[28] Khalid AN, Ladha KS, Luong AU, Quraishi SA. Association of vitamin D status and acute rhinosinusitis: Results from the United States National Health and Nutrition Examination Survey 2001-2006. Medicine 2015; 94: e1447

[29] Koundourakis NE, Avgoustinaki PD, Malliaraki N, Margioris AN. Muscular effects of vitamin D in young athletes and non-athletes and in the elderly. Hormones (Athens) 2016; 15: 471-488 
[30] Kumar ], Muntner P, Kaskel F], Hailpern SM, Melamed ML. Prevalence and associations of 25-hydroxyvitamin D deficiency in US children: NHANES 2001-2004. Pediatrics 2009; 124: e362-e370

[31] Levy MA, McKinnon T, Barker T, Dern A, Helland T, Robertson ], Cuomo J, Wood T, Dixon BM. Predictors of vitamin D status in subjects that consume a vitamin D supplement. Eur J Clin Nutr 2015; 69: 84-89

[32] Macdonald HM. Contributions of sunlight and diet to vitamin D status. Calcif Tissue Int 2013; 92: 163-176

[33] MacLaughlin J, Holick MF. Aging decreases the capacity of human skin to produce vitamin D3. J Clin Invest 1985; 76: 1536-1538

[34] Magee PJ, Pourshahidi LK, Wallace JM, Cleary J, Conway J, Harney E, Madigan SM. Vitamin D status and supplementation in elite Irish athletes. Int J Sport Nutr Exerc Metab 2013; 23: 441-448

[35] Maruyama-Nagao A, Sakuraba K, Suzuki Y. Seasonal variations in vitamin $D$ status in indoor and outdoor female athletes. Biomed Rep 2016; 5: 113-117

[36] Matsuoka LY, Ide L, Wortsman J, MacLaughlin JA, Holick MF. Sunscreens suppress cutaneous vitamin D3 synthesis. J Clin Endocrinol Metab 1987; 64: 1165-1168

[37] Mitchell DM, Henao MP, Finkelstein JS, Burnett-Bowie SA. Prevalence and predictors of vitamin D deficiency in healthy adults. Endocr Pract 2012; 18: 914-923

[38] Moons KG, Donders RA, Stijnen T, Harrell FE Jr. Using the outcome for imputation of missing predictor values was preferred. J Clin Epidemiol 2006; 59: 1092-1101

[39] Moore C, Murphy MM, Keast DR, Holick MF. Vitamin D intake in the United States. J Am Diet Assoc 2004; 104: 980-983

[40] Narayanan DL, Saladi RN, Fox JL. Ultraviolet radiation and skin cancer. Int J Dermatol 2010; 49: 978-986

[41] Ogan D, Pritchett K. Vitamin D and the athlete: Risks, recommendations, and benefits. Nutrients 2013; 5: 1856-1868

[42] Owens D], Fraser WD, Close GL. Vitamin D and the athlete: Emerging insights. Eur J Sport Sci 2015; 15: 73-84

[43] Owens DJ, Sharples AP, Polydorou I, Alwan N, Donovan T, Tang J, Fraser WD, Cooper RG, Morton JP, Stewart C, Close GL. A systems-based investigation into vitamin $\mathrm{D}$ and skeletal muscle repair, regeneration, and hypertrophy. Am J Physiol 2015; 309: E1019-E1031

[44] Peeling P, Fulton SK, Binnie M, Goodman C. Training environment and vitamin D status in athletes. Int J Sports Med 2013; 34: 248-252

[45] Rhodes LE, Webb AR, Fraser HI, Kift R, Durkin MT, Allan D, O'Brien S], Vail A, Berry JL. Recommended summer sunlight exposure levels can produce sufficient ( $>$ or $=20 \mathrm{ng} \mathrm{ml}(-1)$ ) but not the proposed optimal (> or $=32 \mathrm{ng} \mathrm{ml}(-1)$ ) 25(OH)D levels at UK latitudes. J Invest Dermatol 2010; 130: 1411-1418

[46] Rosenstreich SJ, Rich C, Volwiler W. Deposition in and release of vitamin D3 from body fat: Evidence for a storage site in the rat. J Clin Invest 1971; 50: 679-687

[47] Ross AC, Manson JE, Abrams SA, Aloia JF, Brannon PM, Clinton SK, Durazo-Arvizu RA, Gallagher JC, Gallo RL, Jones G, Kovacs CS, Mayne ST, Rosen C], Shapses SA. The 2011 report on dietary reference intakes for calcium and vitamin $D$ from the Institute of Medicine: What clinicians need to know. J Clin Endocrinol Metab 2011; 96: 53-58

[48] Shuler FD, Wingate MK, Moore GH, Giangarra C. Sports health benefits of vitamin D. Sports Health 2012; 4: 496-501
[49] Skaaby T, Husemoen LL, Thuesen BH, Pisinger C, Hannemann A, Jorgensen T, Linneberg A. Longitudinal associations between lifestyle and vitamin D: A general population study with repeated vitamin D measurements. Endocrine 2016; 51: 342-350

[50] Snellman G, Melhus H, Gedeborg R, Byberg L, Berglund L, Wernroth L, Michaelsson K. Determining vitamin $D$ status: A comparison between commercially available assays. PLoS ONE 2010; 5: e11555

[51] STATA. StataCorp. Stata Multiple-Imputation Reference Manual. Release 13. College Station, TX: Stata Press; 2013

[52] Sterne JA, White IR, Carlin JB, Spratt M, Royston P, Kenward MG, Wood AM, Carpenter JR. Multiple imputation for missing data in epidemiological and clinical research: Potential and pitfalls. BMF 2009; 338: b2393

[53] Sundgot-Borgen J, Torstveit MK. Prevalence of eating disorders in elite athletes is higher than in the general population. Clin J Sport Med 2004; 14: 25-32

[54] Swiss Olympic. Swiss Olympic Talent Cards Report 2014. In Swiss Olympic ed. Ittigen, Bern, Switzerland: Swiss Olympic; 2014

[55] Theodoratou E, Tzoulaki I, Zgaga L, Ioannidis JP. Vitamin D and multiple health outcomes: Umbrella review of systematic reviews and meta-analyses of observational studies and randomised trials. BM] 2014; 348: g2035

[56] Tomlinson PB, Joseph C, Angioi M. Effects of vitamin D supplementation on upper and lower body muscle strength levels in healthy individuals. A systematic review with meta-analysis. J Sci Med Sport 2015; 18: 575-580

[57] Tsugawa N, Suhara Y, Kamao M, Okano T. Determination of 25-hydroxyvitamin $\mathrm{D}$ in human plasma using high-performance liquid chromatography--tandem mass spectrometry. Anal Chem 2005; 77: 3001-3007

[58] Vieth R, Kimball S, Hu A, Walfish PG. Randomized comparison of the effects of the vitamin D3 adequate intake versus $100 \mathrm{mcg}$ (4000 IU) per day on biochemical responses and the well-being of patients. Nutr J 2004; 3: 8

[59] Webb AR. Who, what, where and when-influences on cutaneous vitamin D synthesis. Prog Biophys Mol Biol. 2006: 92: 17-25

[60] Webb AR, Kift R, Berry JL, Rhodes LE. The vitamin D debate: Translating controlled experiments into reality for human sun exposure times. Photochem Photobiol 2011; 87: 741-745

[61] Weng FL, Shults ], Leonard MB, Stallings VA, Zemel BS. Risk factors for low serum 25-hydroxyvitamin $D$ concentrations in otherwise healthy children and adolescents. Am J Clin Nutr 2007; 86: 150-158

[62] White IR, Royston P, Wood AM. Multiple imputation using chained equations: Issues and guidance for practice. Stat Med 2011; 30: 377-399

[63] Willis KS, Smith DT, Broughton KS, Larson-Meyer DE. Vitamin D status and biomarkers of inflammation in runners. Open Access J Sports Med 2012; 3: 35-42

[64] Wolman R, Wyon MA, Koutedakis Y, Nevill AM, Eastell R, Allen N. Vitamin $D$ status in professional ballet dancers: Winter vs. summer. J Sci Med Sport 2013; 16: 388-391

[65] World Health Organisation. BMI-for-age (5-19 years). In: Organization WH, ed. World Health Organization. 2006; World Health Organisation Application tools accessed 2017

[66] Wroe AL. Intentional and unintentional nonadherence: A study of decision making. J Behav Med 2002; 25: 355-372 